\title{
ANCHORAGE SYSTEM IN OLD POST-TENSIONED PRECAST BRIDGES
}

\author{
Petra BUJŇÁKOVÁ $1,{ }^{*}$ \\ ${ }^{1}$ Department of Structures and Bridges, Faculty of Civil Engineering, University of Zilina, Univerzitna \\ 8215/1, 01026 Žilina, Slovakia. \\ corresponding author: petra.bujnakova@uniza.sk.
}

\begin{abstract}
The first precast post-tensioned bridges in Slovakia are approaching 60 years of their service life. Facing an aging infrastructure, it is necessary to assess their present structural condition and residual life expectancy. Different types and methods of anchorage system were developed and available for first post-tensioned bridges around the world. The reliability and functionality of anchorages contribute to the proper behaviour of post-tensioning system. The considerable effect of aggressive environment (frost, chloride salts, humidity) and environmental load $\left(\mathrm{CO}_{2}\right)$ leads to corrosion of anchorages and prestressing steel with the risk of a sudden unexpected damage to bridge. The research work deals into finding more details of this structural part. During the demolition of damaged post-tensioned bridges built in 1960s several anchorages were removed and analysed. The material properties, size parameters and performed tensile tests of a wedge anchorage system are summarised in this paper. The findings from this study can be used as input parameters for numerical simulation and durability assessment of similar aged existing post-tensioned bridges.
\end{abstract}

\section{Introduction}

As prestressed concrete started to be used in bridge design and construction after the World War II, it became necessary to establish standard specifications and design practices for concrete and prestressing steel, prestressing technology and anchoring system [1]. Various types of prestressing steel, such as wires, rods, strands were used. Suitable mechanical properties of prestressing steel were obtained by special production processes, especially cold drawn after patenting, refining and alloying. Predominantly, the wires grouped into tendon were used for first post-tensioning system. The tendon was located in the duct. After stressing, the tendon was anchored at one end. The duct was filled with cement paste or mortar to protect the tendon from corrosion. Different anchorage system and methods patented by the manufacturer and prestressing companies have been used for posttensioning around the world in the 20th century. In the case of parallel wire tendons, various devices and methods were available such as wedge system, either a wedge cone (Freyssinet system) or a flat wedge (Mangel system), button heads anchors (BBRV) and looping system (Leoba, Baur-Leonhardt, Korovkin) [2, 3]. The smooth patented wires grouped into the tendon were used for first posttensioning system in Czechoslovakia in the early 1960s and the late 1970s [4]. The original anchorage was based on wedge system following the Freyssinet principle. Currently, the first existing precast post-tensioned bridges are approaching 60 years of their service. The present structural condition of these structures is inappropriate, closely related to their maintenance, inadequate inspection, external loads and careless conceptual design. Damage due to material defects also leads to collapse or severe damage of those bridges [5 - 7]. However, some hidden failures cannot be detected by visual inspection and appropriate diagnostic methods are needed [8 - 10]. An important part of posttensioned bridges is the functional anchorage system and tendon grouting, which contributes to the proper structural system $[11,12]$. With missing grout the bearing capacity of the structure can be lost 
resulting [13]. The ultimate bearing capacity of the girder under anchorage failure condition can be reduced from 3.6 to $10 \%$ [14].

Some first precast post-tensioned bridges in Slovakia were near the collapse state and had to be demolished and rebuilt $[5,6]$. This provided an opportunity to analyse the first anchoring system.

\section{General concept of anchorages}

\subsection{Anchorage system}

Freyssinet has introduced the first most widely used anchor and prestressing system based on wedge principle. Anchorage device consists of a concrete cylinder with a conical hole and a concrete conical wedge. The high strength steel wires are closely spaced around a conical hole. On the tensioned side, all wires are stretched at a time and the conical wedge is pushed into cylinder to grip the wires. The wires are anchored by the action of friction forces. After stressing the anchor acts on the concrete. The cone is equipped with longitudinal grooves that ensure the correct position of the wires. The advantage of such an anchoring system is better friction in the contact of steel with concrete than in steel anchorages. In one tendon there are varying numbers of wires from 8 to 24 wires with a diameter of 5 to $8 \mathrm{~mm}$, which are parallel to each other. Later, the wires were replaced by strands [2, 4].

The Mangel system (Belgium) used a flat metallic anchor plates with wedge cut-outs which gripped two wires by flat wedge. Tendon consists of wires of $5 \mathrm{~mm}$ or $7 \mathrm{~mm}$ in multiples of 4 or 8 wires in horizontal layers in a unit. With a large number of wires (maximum 64), the anchor plates are placed on the top of each other, termed "sandwich plates“. This system is no longer available. In Italy, Morandi developed his own wedge system. The wires are anchored in a cylindrical sleeve in pairs at a time. The Barredo system (Spain) used three wires per tendon with wedge anchoring system [3].

In the BBRV system (Swiss), the single wires are anchored by button heads formed at the end of the wires. This system was developed in 1949 and is well suited for transmitting large forces.

The Baur-Leonhardt system (Germany) is based on looping principle. The wires are anchored at the end with a loop placed around the detached end block. After stretching, the end block is moved and a gap is filled with concrete. This system is suitable for forces up to $36000 \mathrm{kN}$ [2].

\subsection{Anchorage principle}

In former Czechoslovakia, the Horel anchoring wedge system based on the Freyssinet principle was used for first precast post-tensioned bridges $[4,15]$. Concrete anchorages were replaced by a steel anchorage. The anchorage consists of a steel square or a rectangular bearing plate with a conical hole and a steel conical wedge, Fig. 1. The smooth parallel patented wires are distributed evenly around the conical hole of a bearing plate. The wedge is inserted with pressure while wires are kept stretched. The wedge restrains the wires against going inside and the wires retain the prestressing force. The friction forces act along the contacting surface opposite to the wedge movement according the equations (1) and (2):

$T_{1}=N \cdot f_{1}$

$f_{1}$ - the friction coefficient between wire and conical hole in bearing plate (value 0.3 is recommended for use),

$N$ - transverse forces acting on the contacting surface.

$T_{2}=N \cdot f_{2}=N \cdot \operatorname{tg} \alpha$

$f_{2}$ - the friction coefficient between wire and conical wedge. With a small inclination of the cone, the value can be considered as $f_{2}=\operatorname{tg} \alpha$.

The wires are pushed against inside conical surface by radial pressure. The transverse forces act perpendiculary to the inclined surface. Consider the $N_{1}$ equals to $N_{2}$ from the balance of forces acting on the wedge cone and wires, the transverse force acting on one wire should by described by expression (3): 
$N=\frac{n P+S / \cos \alpha}{n\left(f_{1}+\operatorname{tg} \alpha\right)}$

$P$ - prestressing force,

$n$ - number of prestressing wires,

$S$ - pushing force on the wedge.

The transverse force acting on wedge without considering the pushing force on the wedge can be obtained from the relationship (4):

$N=\frac{P}{\left(f_{1}+f_{2}\right)}=\frac{P}{\left(f_{1}+\operatorname{tg} \alpha\right)}$.

The anchor transfers prestressing force into member. Bearing plate retains the transverse tension from horizontal force caused by the pressure of the wedge and transmits the bearing stress $\sigma_{c}$ to the face of the concrete member. The horizontal force compresses and narrows the wedge, its reaction $H$ tries to tear the bearing plate, and can be determined as:

$H=N \cos \alpha-f_{1} N \sin \alpha=\frac{P}{f_{1}+t g \alpha}\left(\cos \alpha-f_{1} \sin \alpha\right)$.
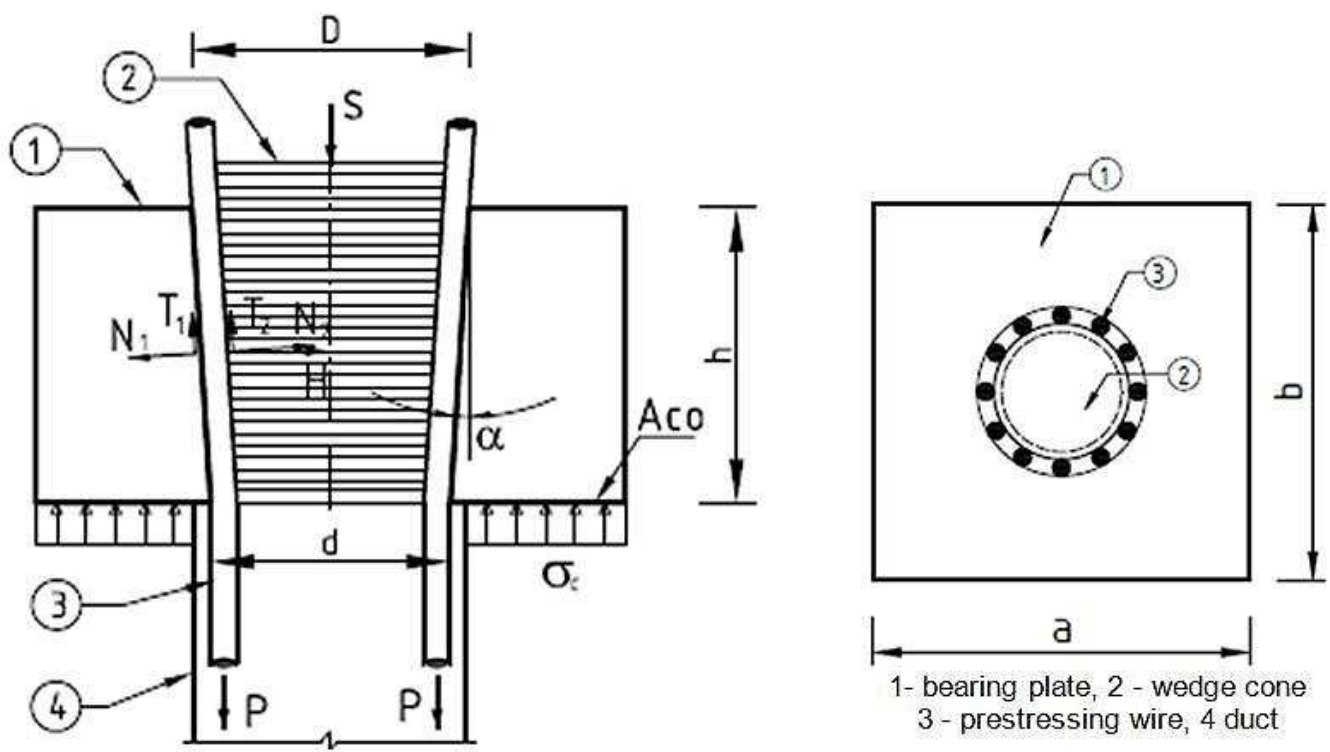

Fig. 1: Anchorage arrangement: a) section; b) ground plan view.

The disadvantage of this system is a slip at anchorage in stressing phase, which causes the loss of stress in tendon. The maximum values of wire slip at anchorage are given in Table 1 [4].

Table 1: Recommended values of maximum slip at anchorage in stressing phase.

\begin{tabular}{|c|c|c|c|c|c|c|}
\hline Type of anchorage & $\mathbf{7} \boldsymbol{\phi} \mathbf{P 4 . 5}$ & $\mathbf{9} \boldsymbol{\phi} \mathbf{P 4 . 5}$ & $\mathbf{1 3} \boldsymbol{\phi} \mathbf{P 4 . 5}$ & $\mathbf{2 0} \boldsymbol{\phi} \mathbf{P} 4.5$ & $\mathbf{1 2} \boldsymbol{\phi} \mathbf{P 7}$ & $\mathbf{2 4} \boldsymbol{\phi} \mathbf{P 7}$ \\
\hline Max. slip at anchorage $[\mathrm{mm}]$ & 3.2 & 3.5 & 5 & 6 & 6 & 9 \\
\hline
\end{tabular}

According to existing practices from 1960 [15], the following allowable bearing stress limitations for anchorages enclose to end part of concrete member are recommended:

$\sigma_{c}=\frac{n P}{A_{c o}} \geq 1.6 \sqrt[3]{\frac{A_{c 1}}{A_{c o}}} k_{b} \leq 2,5 . k_{b}$

$A_{c o}$ - net bearing area, specified according to (7),

$A_{c 1}$ - design distribution area, the largest area of the concrete supporting surface of the net bearing area. The dimension must not be greater than 5 times of the net bearing area $A_{c o}$,

$k_{b}$ - allowable compressive stress of concrete. 
$A_{c o}=a \cdot b-\pi d^{2} / 4$

$a, b$ - dimensions of an anchorage,

$d$ - bottom diameter of bearing plate.

The bearing stress ahead of anchor is closely related with geometry of anchorages. It was recommended to observe the ratio $A_{c 1} / A_{c o}=3.818$ for an economical anchoring. The supplementary reinforcement ahead of anchor is needed to resist transverse tension (bursting and spalling forces). The spiral reinforcement is intended to enhance the bearing strength of concrete. The spiral length is recommended to 1.5 times the diameter of the spiral or twice the width of the bearing plate. In general, the amount and distribution of reinforcement in anchorage zone is based on Guyon's theory on a two dimensional elastic analysis of a three-dimensional system of stress. The distribution steel area is recommended in region from $0.2 \mathrm{~h}$ to $1.0 \mathrm{~h}$ ( $\mathrm{h}$ beam depth) from the loaded end face.

The bearing stress behind the anchorage according to current design practice Eurocode EN 1992-1-1 [16] is specified as:

$\sigma_{c}=\frac{F_{R d u}}{A_{c o}} \geq f_{c d} \sqrt{\frac{A_{c 1}}{A_{c o}}} \leq 3.0 f_{c d}$

$f_{c d}$ - design compressive strength of the concrete,

$F_{R d u}$ - design resistance,

$A_{c 1}$ - design distribution area, the largest area of the concrete supporting surface of the net bearing area. The dimension must not be greater than 3 times of the net bearing area $A_{c o}$.

\section{Investigation of anchorages}

Three first post-tensioned precast bridges built in 1960's near the collapse state condition were demolished and rebuilt. Partial failures and structural damage result especially from conceptual design, inadequate maintenance and overloading of structure. After visual inspection of anchorage zone some following signs were indicated:

- Water leakage, some anchorage that were not concreted were corroded, especially in the area behind the wedge cone,

- Most cable ducts have not been injected,

- Spalls at anchorages,

- Wire breaking at the point of output of bearing plate.

\subsection{Types of anchorages}

Several anchorages removed from bridges were analysed in laboratory. The type, number and arrangement of anchorage depends on the amount of prestressing. Various types of anchorages are shown in Fig. 2a. Simple anchorage was used to anchor one tendon, in Fig. 2b. The anchor consists of a square or rectangular bearing plate $(a x b)$ with a conical hole and a steel conical wedge, see Fig. 2c. Anchorage dimensions are listed in Table 2. The wedge cone has transverse grooves to increase friction. Its depth $h_{w}$ depends on the contacting surface between the cone and wires and on the roughness of the conical hole, see Table 3 . Smooth patented wires (from 7 to 24) with nominal diameter of $4.5 \mathrm{~mm}$ or $7 \mathrm{~mm}$ were grouped in cable and used in bridge structures. The cable was injected in the gaps between wires. Some wedges have a hole for grouting in the middle of the cone. Multi anchors were used to anchor two or more tendons, Fig. 2a. Several conical holes are placed in one rectangular bearing plate. The dimension of bearing plate range from $30 \times 80 \mathrm{~mm}$ to $50 \times 120$ $\mathrm{mm}$. The angle of inclination of the wedge $\alpha$ ranges between 5 to 10 degrees. 

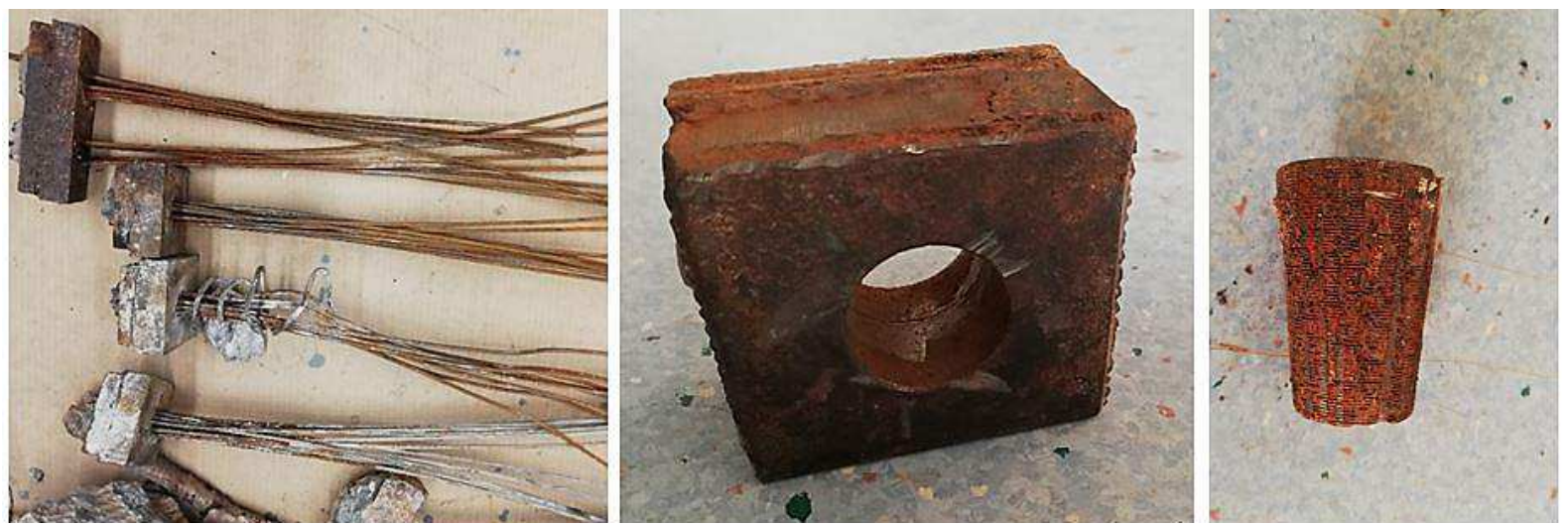

Fig. 2: a) Anchorages from damaged bridges; b) Simple steel anchorage; c) Wedge cone.

Table 2: Simple anchorage dimensions.

\begin{tabular}{|c|c|c|c|c|}
\hline Anchorage & $\mathbf{1 3} \boldsymbol{\phi} \mathbf{P 4 . 5}$ & $\mathbf{2 0} \boldsymbol{\phi} \mathbf{P 4 . 5}$ & $\mathbf{1 2} \boldsymbol{\phi} \mathbf{P 7}$ & $\mathbf{2 4} \boldsymbol{\phi} \mathbf{P 7}$ \\
\hline Dimension of plate $a[\mathrm{~mm}]$ & 90 & 120 & 120 & 200 \\
\hline Dimension of plate $b[\mathrm{~mm}]$ & 90 & 120 & 120 & 200 \\
\hline Thickness $h[\mathrm{~mm}]$ & 40 & 60 & 60 & $70+25$ \\
\hline Upper diameter $D[\mathrm{~mm}]$ & 39 & 50.5 & 50.5 & 145 \\
\hline Bottom diameter $d[\mathrm{~mm}]$ & 32 & 40 & 40 & 52 \\
\hline
\end{tabular}

Table 3: Dimension of steel wedge.

\begin{tabular}{|c|c|c|c|c|}
\hline Anchorage & $\mathbf{1 3} \boldsymbol{\phi} \mathbf{P} \mathbf{4 . 5}$ & $\mathbf{2 0} \boldsymbol{\phi} \mathbf{P} \mathbf{5} \mathbf{5}$ & $\mathbf{1 2} \boldsymbol{\phi} \mathbf{P 7}$ & $\mathbf{2 4} \boldsymbol{\phi} \mathbf{P 7}$ \\
\hline Depth $h_{w}[\mathrm{~mm}]$ & 40 & 57 & 60 & 70 \\
\hline Diameter $d_{w}[\mathrm{~mm}]$ & 23.7 & 30.7 & 26.8 & 41.5 \\
\hline
\end{tabular}

\subsection{Material properties}

The wires, produced through a special heat-treatment process "patenting" were used as a basic material for first post-tensioning in Slovakia. The patented wire has a high tensile strength of 1400 to $2000 \mathrm{MPa}$, an elongation of 2 to $4 \%$ and modulus of elasticity of $190 \mathrm{GPa}$, see Table 4 . The final wire strength depends on the chemical composition and the degree of cold drawing [17, 18]. The patented wire is sensitive to mechanical surface damage, bends and high temperatures. No welding is allowed after patenting.

Table 4: Characteristics of patented wires.

\begin{tabular}{|c|c|c|c|c|c|c|}
\hline Wires & $\begin{array}{c}\text { Nominal } \\
\text { cross-sectional } \\
\text { area } A_{p 1}\left[\mathrm{~mm}^{2}\right]\end{array}$ & $\begin{array}{c}\text { Ultimate } \\
\text { tensile strength } \\
\sigma_{p t}[\mathrm{MPa}] \\
\end{array}$ & $\begin{array}{c}\text { Yield strength } \\
\sigma_{0,2}[\mathrm{MPa}]\end{array}$ & $\begin{array}{l}\text { Ductility } \\
\delta \text { [\%] }\end{array}$ & $\begin{array}{c}\text { Modulus } \\
\text { of elasticity } \\
E_{p}[\mathrm{GPa}] \\
\end{array}$ & $\begin{array}{l}\text { Weight } \\
\text { of wires } \\
m[\mathrm{~g} / \mathrm{m}]\end{array}$ \\
\hline$\phi P 4.5$ & 15.904 & 1650 & 1200 & 2.6 & \multirow{2}{*}{190} & 124.85 \\
\hline$\phi P 7$ & 38.484 & 1400 & 1000 & 3.4 & & 302.10 \\
\hline
\end{tabular}

The allowable stress of the patented wire at stressing is determined as 0.935 times the guaranteed yield strength corresponding to a permanent elongation of $0.2 \%\left(0.935 \sigma_{0,2}\right)$, [15]. The calculated mechanical properties at stressing phase are illustrated in Table 5.

Table 5: Mechanical properties during the stressing phases.

\begin{tabular}{|c|c|c|c|c|c|c|}
\hline Type of anchorage & $\mathbf{7} \boldsymbol{\phi} \mathbf{P 4 . 5}$ & $\mathbf{9} \boldsymbol{\phi} \mathbf{P} \mathbf{4 . 5}$ & $\mathbf{1 3} \boldsymbol{\phi} \mathbf{P 4 . 5}$ & $\mathbf{2 0} \boldsymbol{\phi} \mathbf{P 4 . 5}$ & $\mathbf{1 2} \boldsymbol{\phi} \mathbf{P 7}$ & $\mathbf{2 4} \boldsymbol{\phi} \mathbf{P 7}$ \\
\hline Tendon area $A p\left[\mathrm{~mm}^{2}\right]$ & 111.33 & 143.14 & 206.75 & 318.08 & 461.81 & 923.62 \\
\hline $\begin{array}{c}\text { Max. stressing force } \\
P[\mathrm{kN}]\end{array}$ & 124.91 & 160.61 & 231.98 & 356.87 & 431.80 & 863.59 \\
\hline $\begin{array}{c}\text { Min. pushing force on wedge } \\
S[\mathrm{kN}]\end{array}$ & 30 & 40 & 60 & 90 & 90 & 200 \\
\hline
\end{tabular}




\section{Performed tests and discussion}

Anchorages in relatively good condition have been gradually tested. The anchorage system from bridge Podbiel is described below. This bridge was built in 1956. The superstructure composed of 10 post-tensioned precast T girders with 22 parabolic tendons. Each tendon consists of 12 or 10 patented wires of steel type $\phi$ P 4.5 (120/165). Precast girders were transformed into an orthotropic deck. Girders were connected by cross beams and post-tensioned with 11 tendons and transversally post-tensioned through the top flange. This solution was developed for short span bridges (up $30.0 \mathrm{~m}$ ) and it is not used today. The major case of damage of this bridge structure was determined to brittle failure [5].
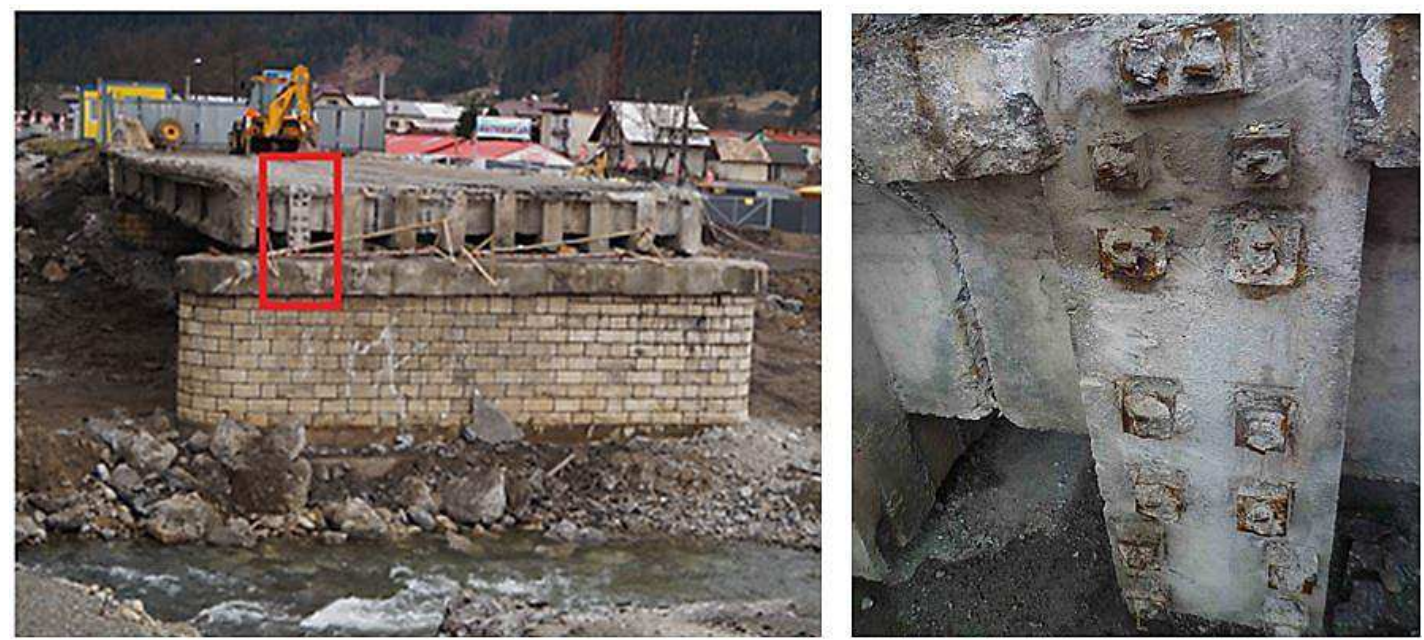

Fig. 3: a) Demolition of damaged bridge, b) View on the anchorage area.

Two single anchorages in visual the best condition were tested. Each anchorage consists of 10 high steel smooth patented wires with diameter of $4.5 \mathrm{~mm}(10 \varnothing \mathrm{P} 4.5 \mathrm{~mm})$. The wires were stressrelieved steel wires. The cross-sectional area $A_{p 1}$ of a single wire is $15.9 \mathrm{~mm}^{2}$. The strength of the wires was tested by standard method, the mean measured strength of a single wire $f_{p}$ was $1647 \mathrm{MPa}$ and mean yield strength $f_{y}$ was $1160 \mathrm{MPa}$, as shown in Table 6.

Table 6: Mean measured mechanical properties of smooth patented wires.

\begin{tabular}{|c|c|c|c|}
\hline Wire & $\begin{array}{c}\text { Nominal cross-sectional } \\
\text { area } A_{p 1}\left[\mathrm{~mm}^{2}\right]\end{array}$ & $\begin{array}{c}\text { Tensile strength } \\
f_{p}[\mathrm{MPa}]\end{array}$ & $\begin{array}{c}\text { Yield strength } \\
f_{y}[\mathrm{MPa}]\end{array}$ \\
\hline$\phi \mathrm{P} 4.5$ & 15.904 & 1647 & 1160 \\
\hline
\end{tabular}

The special single square anchorage was made with two flat steel bearing plates with a conical hole and a one conical steel wedge, see Fig. 4. The net bearing plate size is $100 \times 100 \mathrm{~mm}$ and thickness of $20 \mathrm{~mm}$. The upper plate size is $80 \times 80 \mathrm{~mm}$ with thickness of $30 \mathrm{~mm}$. The depth of wedge cone is $55 \mathrm{~mm}$. The wedge cone has grooves on its surface with thickness of $0.5 \mathrm{~mm}$. The grooves on the wedge are not symmetrical; they are adjusted to prevent the slip of prestressing wires. The inclination of wedge cone is $5.15^{\circ}$. 


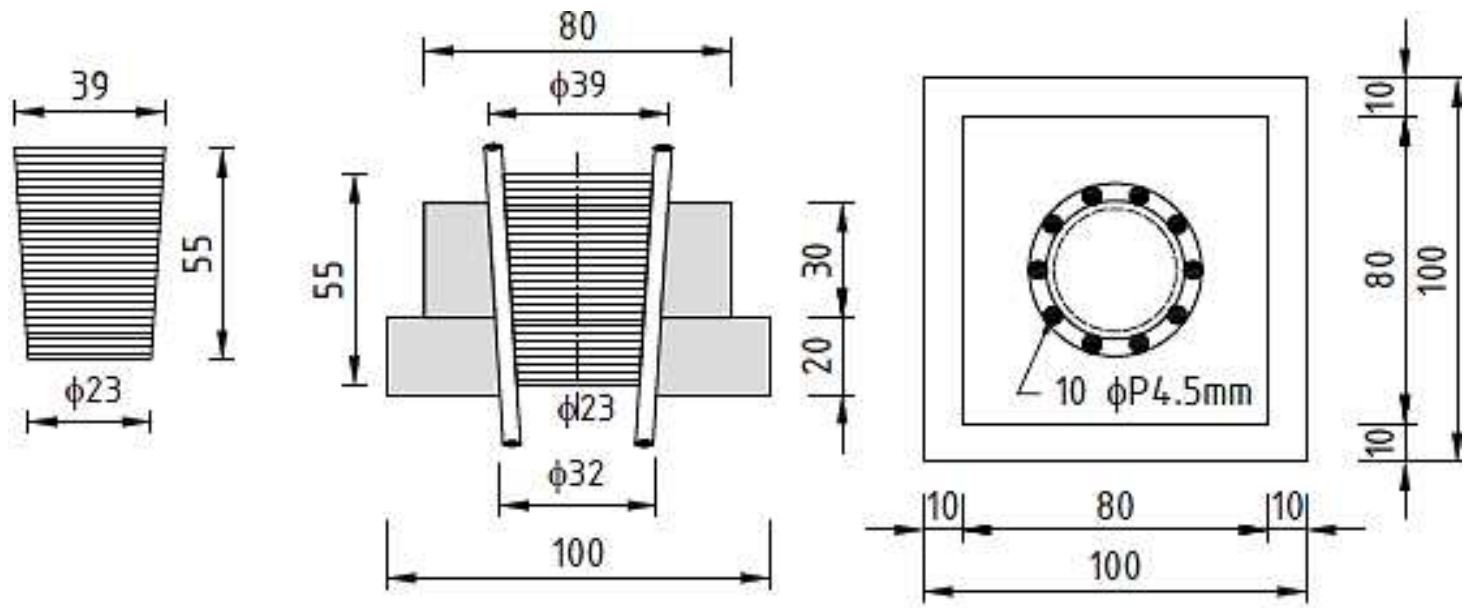

Fig. 4: Anchorage arrangement: a) steel wedge; b) anchorage system.

The real working life of tested anchorages was 59 years. The function of these anchorages was verified by a short-term single tensile test in soft load mode. The test verifies how the tensile strength of wires decreases by the action of the anchorage. It is required that the tensile strength of wires in the anchorage does not decrease to 0.90 times. A value of 0.95 is recommended when randomly selecting anchorage for the test [15].

$\frac{N_{p u m}}{N_{p m}} \geq 0.95$,

$N_{\text {pum }}$ - failure load measured in the test,

$N_{p m}$ - ultimate tensile force.

The installation of a testing setup is shown in Fig. 5. The bearing plate and a wedge cone from another anchorage were used for the fixation of the test anchorage. Thus formed test specimen was extruded by hydraulic jack (Enerpac) with capacity $1000 \mathrm{kN}$. The load was recorded. The elongation was measured by using linear variable position transducers (TR 50) placed on both sides of specimen. The view on anchorage $\mathrm{A} 1$ before and after testing is shown in Fig. $5 \mathrm{~b}$ and Fig. $5 \mathrm{c}$. The relation between applied load and the elongation is illustrated in Fig. 6 .
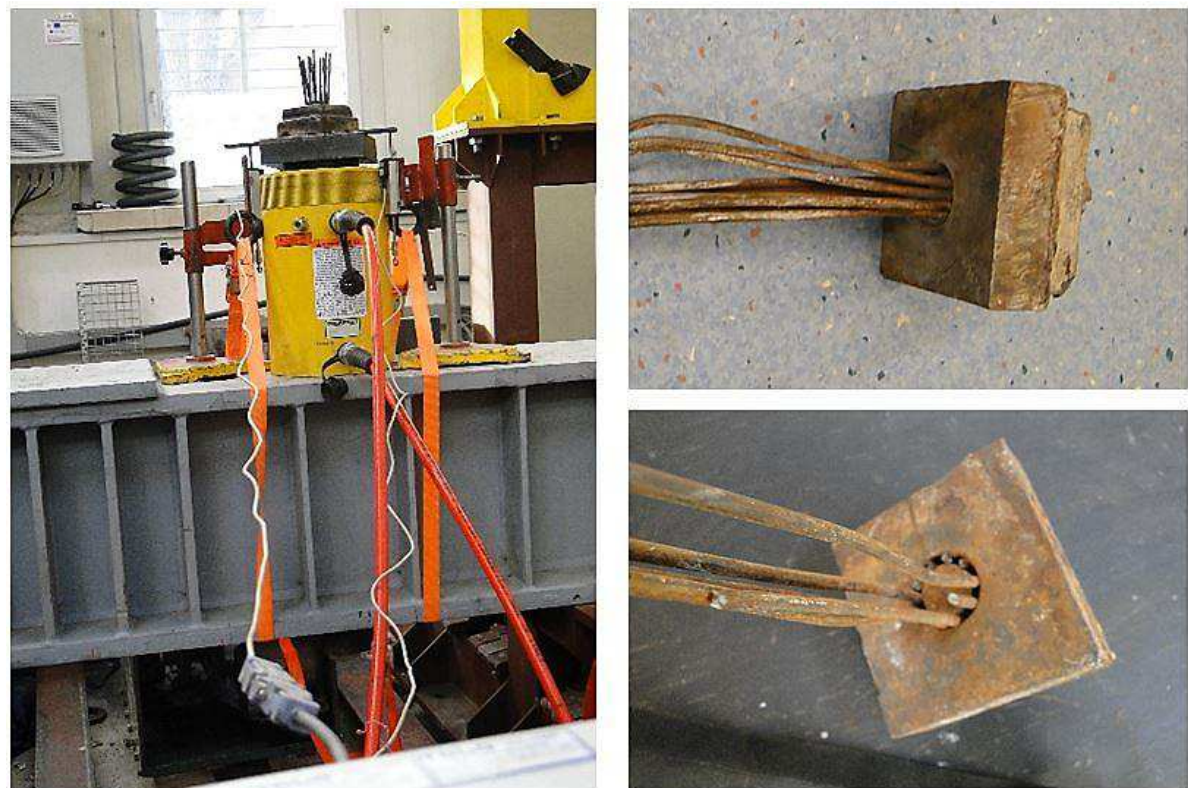

Fig. 5: a) Test setup; b) Anchorage before testing; c) Anchorage after testing.

During the tests, the wires and the wedge cone were pulled into the bearing plate simultaneously. The wedge inclination is small of $5.15^{\circ}$. The friction between wire and wedge cone 
may be assumed to the value $\operatorname{tg} \alpha$. In future, the real friction coefficient will be verified during testing. As it can be seen from Fig. 6, the behaviour is not linear. Slippage occurs in three wires during the test 1 . Assuming the corrosion surface and small inclination of the wedge cone it could affect the wire slippage during the testing. After reaching the limit of elasticity the wires were broken. The failure load of both anchorages is presented in Table 7. The measured mechanical properties of wires have taken into calculation of ultimate tensile force $(262.4 \mathrm{kN})$. The ultimate tensile load decreases by $15 \%$ (anchor A1) and $23 \%$ (anchor A2). The elongation in both specimens is very similar as shown in Fig. 6.
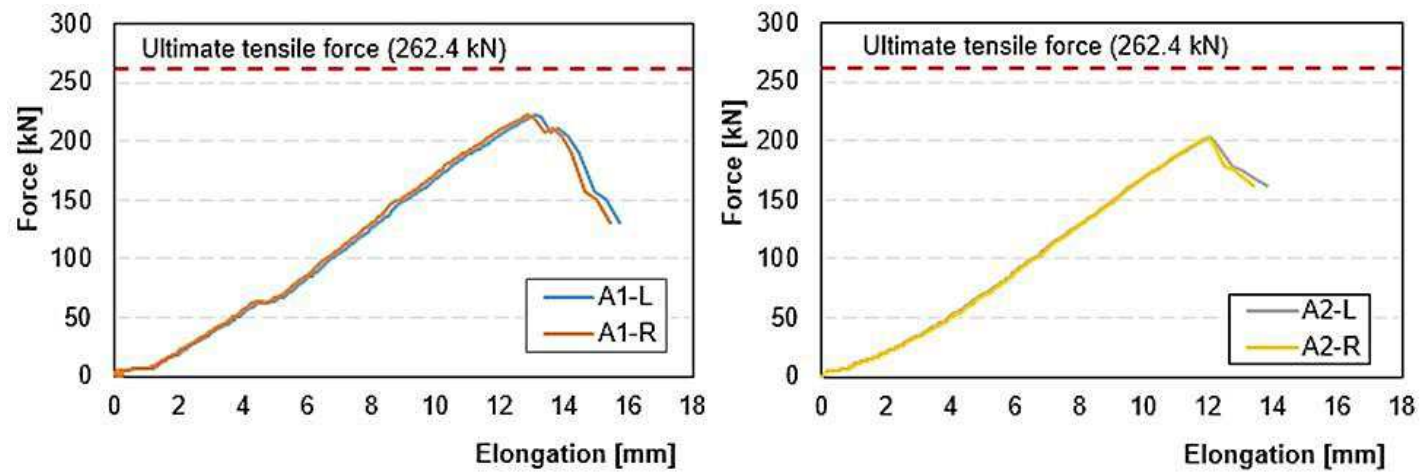

Fig. 6: Load versus elongation of wires (10 $\phi P$ 4.5): a) anchor $A 1$; b) anchor $A 2$.

Table 7: Tensile resistance of anchorages.

\begin{tabular}{|c|c|c|c|c|}
\hline Anchorage & $\begin{array}{c}\text { Number of patented } \\
\text { wires P } \mathbf{\phi} 4.5\end{array}$ & $\begin{array}{c}\text { Ultimate tensile } \\
\text { force } \boldsymbol{N}_{\text {pm }}[\mathbf{k N}]\end{array}$ & $\begin{array}{c}\text { Mesured force } \\
\boldsymbol{N}_{\text {pum }}[\mathbf{k N}]\end{array}$ & \multirow{2}{*}{$\boldsymbol{N}_{\text {pum }} / \boldsymbol{N}_{\text {pm }}$} \\
\hline A1 & 10 & \multirow{2}{*}{262.4} & 222.46 & 0.85 \\
\cline { 1 - 2 } \cline { 5 - 6 } & 10 & & 202.93 & 0.77 \\
\hline
\end{tabular}

\section{Conclusions}

The analysed wedge anchorage system was used in first post-tensioned precast bridges in Slovakia in the 1960s. Based on this study the following conclusions can be drawn:

- The anchorages were made of corrosion non resisting material. They were not sufficiently embedded and concreted, which caused their corrosion.

- The anchoring of patented wires in wedge anchorages depends on friction and an inclination of the wedge cone and their surface condition.

- The tensioned wires bend at the point of output from conical hole in bearing plate into duct and additional stresses are created. The wires are abraded by pushing the wedge cone and the wire profile is weakened.

At the time of construction of these bridges, simplified empirical models were used to design the anchorage area. Nowadays, the reliability of anchorage systems can be verified using numerical models. Dimensions of anchorage, especially original net bearing plates could not be satisfied for current design practice for bridges. All material specification of post-tensioning components has been assessed in accordance with ETAG 013 [19]. The results of this study will be used as input data for the evaluation of the service life and durability of similar existing bridge structures.

\section{Acknowledgement}

This research work was supported by The Slovak Scientific Grant Agency under contract No. 1/0045/19 and No. 1/0343/18.

\section{References}

[1] Guidance for design of bridges. Regulation for railway and road bridges. SNM, Praha, 1951.

[2] LEONHARDT, F.: Prestressed Concrete Design and Construction. Wilhelm Ernest and Sohn, Berlin, 1964.

[3] ABELES, P. W. - BARDHAN-ROY, B. K.: Prestressed concrete designer's handbook. $3^{\text {rd }}$ edition, Taylor and Francis Group, 1981.

[4] VOVES, B.: Technology of prestressed concrete. SNTL, Praha, 1976. 
[5] MORAVCIK, M. - BUJNAKOVA, P. - BAHLEDA, F: Failure and damage of a first-generation precast prestressed bridge in Slovakia. Structural Concrete, 2020, pp. 1-10.

[6] KOTEŠ, P. - BRODŇAN, M. - BAHLEDA, F.: Diagnostics of Corrosion on a Real Bridge Structure. Advances in Materials Science and Engineering, Vol. 2016, 10 pages, https://doi.org/10. $1155 / 2016 / 2125604$.

[7] PAULÍK, P. et al.: Experimental evaluation of properties of 120 years old concretes at two concrete bridges in Slovakia. International Multidisciplinary Scientific GeoConference Surveying Geology and Mining Ecology Management, SGEM, 249, 2016, pp. 227-234.

[8] VIČAN, J. et al..: Existing steel bridges evaluation. Civil and Environmental Engineering, 2016, Vol. 12 (2), pp. 103-110, https://doi.org/10.1515/cee-2016-0014.

[9] KORTIS, J. et al.: Operational modal analysis of the cable stayed footbridge. Civil and Environmental Engineering, 2017, Vol. 13 (2), pp. 92-98, https://doi.org/10.1515/cee-2017-0012.

[10] BAGGE, N.: Demonstration and examination of a procedure for successively improved structural assessment of concrete bridges. Structural Concrete, 2019, pp. 1-24, https://doi.org/ $10.1002 /$ suco.201900265.

[11] GREGOROVÁ, V. - ŠTEFUNKOVÁ, Z. - LEDEREROVÁ, M.: Experimental investigation of the influence of the plasticizing agent on the properties of cement mortars. IOP Conference Series: Materials Science and Engineering, June, 549, 2019, DOI:10.1088/1757-899X/549/1/012017.

[12] KOMÁRKOVÁ, T. - LÁNIK, J. - ONDŘEJ, A.: Quality Control of the Anchoring of Steel Bridge Barriers by Non-Destructive Testing. Safety, Vol. 6, (2), 2020, https://doi.org/10.3390/ safety6010002.

[13] LACO, J. - BORZOVIC, V.: Experimental Investigation of Prestressing Strand Bond on Behavior of Concrete Members. Structural Concrete, Vol. 114 (1), 2017, pp. 15-24, https://doi.org/10. 1002/suco.201900526.

[14] ZHOU, L. et al.: Experimental investigation of simply-supported post-tensioned beam after anchorage system failure. Engineering Structures, Vol. 212, 2020, pp. 1-9.

[15] ČSN 742870: Steel anchorages of tendons in post-tensioned concrete structures. ÚNM, Praha, 1973.

[16] EN 1992-1-1: Design of concrete structures- Part 1-1. General rules and rules for buildings. European Committee for Standardization, Brussels, 2004.

[17] NESLUŠAN, M. et al: Assessment of Tendon Prestressing after Long-Term Service via the Barkhausen Noise Technique. Materials, Vol. 12, (20), 2019, p. 3450, https://doi.org/10. 3390/ma12203450.

[18] NESLUŠAN, M. et al.: Non-destructive monitoring of corrosion extent in steel rope wires via Barkhausen noise emission. J. of Magnetism and Magnetic Material. Vol. 484, 2019, pp. 179187, https://doi.org/10.1016/j.jmmm.2019.04.017.

[19] ETAG 013: Guideline for European technical Approval of post-tensioning kits for prestressing of structures. EOTA, Brussels, 2002. 